\title{
IDENTIFIKASI DAN ANALISIS STRUKTUR RANTAI PASOK KOPI RAKYAT ROBUSTA KECAMATAN BANGSALSARI, JEMBER
}

Identification and Analysis of Supply Chain Structure on Smallholder Robusta Coffee in Bangsalsari District, Jember Regency

\author{
Novita Fitri Yulian ${ }^{1) *}$, Nita Kuswardhani ${ }^{1)}$, Winda Amilia ${ }^{1)}$ \\ ${ }^{1)}$ Prodi Teknologi Industri Pertanian, Fakultas Teknologi Pertanian, Universitas Jember \\ Jalan Kalimantan No. 37, Kampus Tegal Boto, Jember, Jawa Timur 68121 \\ *Korespondensi Penulis: novitayulian03@gmail.com
}

\begin{abstract}
Robusta coffee is one of the crops plantation that cultivated in the most area in Indonesia. Bangsalsari District, Jember Regency is one of location area on the Argopuro Mountain slope, with total Robusta coffee production about 9,945.80 quintals in 2016. The robusta coffee supply chain is a supply concept which has system settings related to product flow, information flow, financial flow, service flow and actor complicity in each flow. The purpose of this study was to determined the structure of the robusta coffee supply chain in Bangsalsari District, Jember Regency. The data collecting method used in this research were primary and secondary data. The primary data was taken from the results of interviews, observation and documentation, while secondary data obtained from the literature studies, internet, journals and other documents as relevant references. The results showed that the structure of the robusta coffee supply chain in Bangsalsari District, consisted of several supply chain groups or called actors. Supply chain groups were farmers, collectors, wholesalers, exporters and related institutions.
\end{abstract}

Keywords: actor, robusta coffee, supply chain

\section{PENDAHULUAN}

Indonesia memiliki sumber daya alam yang melimpah baik yang ada di darat maupun di laut. Sumber daya alam darat meliputi sektor pertanian, peternakan dan perkebunan. Sektor perkebunan khususnya kopi memiliki luas areal 1,2 juta Ha dan produksi kopi 655.256 ton pada tahun 2015 (Dirjen Perkebunan, 2016). Kabupaten Jember merupakan salah satu daerah yang mengembangkan kopi robusta. Produksi kopi robusta Jember pada tahun 2010 sebesar 3.120 ton dengan luas areal perkebunan 5.608 Ha (Dirjen Perkebunan, 2011). Lereng Pegunungan Argopuro Kabupaten Jember pada tahun 2013 memiliki luas areal kopi robusta masing-masing 125,29 $\mathrm{Ha}, 255,47 \mathrm{Ha}$, $290,00 \mathrm{Ha}, 388,39 \mathrm{Ha}$ dan 107,82 Ha. Produksi kopi robustanya masing-masing mencapai 359,98 ton, 644,20 ton, 819,80 ton, $1.237,49$ ton dan 354,31 ton.
Proyeksi konsumsi kopi Indonesia pada tahun 2016-2020 diperkirakan akan mengalami kenaikan $2,49 \%$ per tahun (Pusat Data dan Sistem Informasi Pertanian Sekretariat JenderalKementerian Pertanian, 2016). Dari total produksi kopi di Kabupaten Jember sebanyak $80-90 \%$, kopi robusta yang dihasilkan petani dijual kepada tengkulak baik untuk pasokan eksportir maupun pedagang besar. Namun, fluktuasi harga mengakibatkan adanya ketidakseimbangan antara permintaan pasar dengan persediaan komoditas kopi sehingga menyebabkan risiko rantai pasok kopi robusta.

Menurut Jebarus dalam Budiono (2016), manajemen rantai pasok merupakan pengembangan lebih lanjut dari konsep tataniaga dalam pemenuhan kebutuhan konsumen. Rantai pasok (supply chain) merupakan hubungan keterkaitan antara aliran material atau jasa, 
aliran uang (return/recycle) dan aliran informasi dari semua aktor (actors) rantai pasok. Aktor yang dimaksud merupakan pelaku dalam rantai pasok mulai dari pemasok, produsen, distributor, gudang, pengecer sampai ke pelanggan akhir atau konsumen. Menurut Suryaningrat (2016) supply chain (rantai pasok) merupakan suatu jaringan organisasi yang memiliki tujuan bersama untuk menciptakan dan mengantarkan produk sampai ke tangan konsumen akhir. Kegiatannya di mulai dari mengubah sumber daya alam dan bahan baku menjadi produk yang disalurkan ke konsumen akhir. Informasi tentang harga, kualitas dan ketersediaan juga diperlukan guna mendukung kegiatan rantai pasok.

Aplikasi manajemen risiko dan rantai pasok telah dilakukan untuk mengatasi beberapa permasalahan di industri. Pada bidang industri pangan berupa makanan ringan berbasis umbiumbian di Kota Padang, industri tersebut menerapkan praktik manajemen rantai pasok dan budaya organisasi sehingga memberikan kontribusi lebih baik sebesar $80 \%$ terhadap kinerja rantai pasok pada sub-sektor industri (Nesti et al., 2016). Aini et al. (2014) menyebutkan bahwa manajemen risiko dan rantai pasok kakao di Indonesia dapat meningkatkan produktivitas dan daya saing kakao. Rantai pasok juga dapat memberikan beberapa alternatif strategi terkait peningkatan daya saing, seperti pada produk tepung terigu di Kabupaten Jember (Purnomo et al., 2014).

Pada proses ekspor, seringkali terjadi ketidakseimbangan antara pasokan ekspor dan penurunan kualitas yang menyebabkan pendapatan petani kopi robusta mengalami penurunan. Kondisi tersebut terjadi di Kecamatan Bangsalsari Kabupaten Jember sehingga dapat menyebabkan risiko rantai pasok dan menimbulkan kerugian di setiap anggota rantai pasok. Oleh karena itu diperlukan analisis yang mendalam mengenai struktur rantai pasok kopi robusta Kecamatan Bangsalsari kabupaten Jember.

\section{METODE PENELITIAN}

\section{Alat dan Bahan}

Alat yang digunakan dalam penelitian ini adalah komputer dengan program Microsoft word 2010 dan Microsoft visio 2010. Bahan yang digunakan dalam penelitian ini yaitu data primer dan data sekunder. Data primer diperoleh melalui observasi lapang di perkebunan kopi rakyat robusta Kecamatan Bangsalsari Kabupaten Jember, wawancara dengan pelaku rantai pasok dan pendapat 4 pakar. Sementara data sekunder diperoleh melalui studi literatur, jurnal ilmiah, dan berbagai sumber seperti dari Dinas Pertanian Tanaman Pangan, Holtikultura dan Perkebunan Kabupaten Jember.

\section{Tahapan Penelitian}

Penelitian dilakukan melalui wawancara langsung pada petani dan kelompok tani tingkat desa. Penelitian dilakukan untuk mengumpulkan informasi sehingga dapat menentukan kondisi permasalahan yang akan diteliti dan dilakukan studi literatur untuk mendapatkan teori yang sesuai. Penelitian dilakukan melalui focus group discussion (FGD) dengan 20 petani kopi robusta. Tahap FGD bertujuan untuk mengetahui struktur beserta actor atau pelaku rantai pasok yang terlibat dalam rantai pasok kopi robutsa.

\section{Metode Analisis Data}

Jenis data dalam penelitian ini terbagi menjadi dua sumber data yaitu data primer dan data sekunder. Data primer merupakan data yang berupa data kualitatif dan kuantitatif yang diperoleh dari wawancara, observasi lapang, dan dokumentasi. Data sekunder diperoleh melalui studi pustaka, penelusuran dari 
internet, berbagai jurnal serta dokumendokumen lain sebagai pendukung yang relevan.

Data mengenai rantai pasok meliputi, struktur, mekanisme, proses pemasaran, peran pihak ketiga, proses bisnis, sumber daya dan manajemen rantai pasok yang didapatkan dari wawancara dari petani kopi robusta Pegunungan Argopuro Kecamatan Bangsalsari Jember secara sampling. Data yang diperoleh hasil FGD (wawancara) berupa pola struktur rantai pasok kemudian digambar menggunakan Microsoft Visio 2010 seperti ditunjukkan pada Gambar 1.

\section{HASIL DAN PEMBAHASAN}

\section{Gambaran Umum Perkebunan Rakyat Kopi Robusta Pegunungan Argopuro Kecamatan Bangasalsari Jember}

Kawasan Pegunungan Argopuro Jember merupakan salah satu kawasan pegunungan yang menghasilkan kopi khususnya jenis robusta (Dinas Pertanian Tanaman Pangan, Holtikultura dan Perkebunan Kab. Jember, 2016). Kabupaten Jember yang terletak di lereng Pegunungan Argopuro meliputi 6 Kecamatan yaitu, Sumberbaru, Tanggul, Bangsalsari, Panti, Sukorambi dan Arjasa. Enam kecamatan tersebut merupakan penghasil kopi yang dikelola oleh petani rakyat bersama dengan kelompok tani. Produksi kopi dari enam Kecamatan tersebut pada tahun 2016 ditunjukkan pada Tabel 1.

Kecamatan Bangsalsari merupakan penghasil kopi terbanyak dibandingkan dengan kecamatan lainnya, sehingga wilayah penelitian difokuskan pada Kecamatan Bangsalsari Kabupaten Jember. Kegiatan usaha tani kopi robusta Kecamatan Bangsalsari di dalamnya terdapat empat kelompok tani tingkat desa. Empat desa yang memiliki kelompok tani tersebut diantaranya yaitu Desa Curah Kalong, Desa Tugusari, Desa
Badean, dan Desa Banjarsari. Masingmasing desa yang memiliki kelompok tani yang ditunjukkan pada Tabel 2.

Tabel 1. Produksi kopi rakyat robusta di Kabupaten Jember pada tahun 2016

\begin{tabular}{lc}
\hline Kecamatan & Produksi $(\mathrm{kw})$ \\
\hline Sumberbaru & $5.446,36$ \\
Tanggul & $4.350,83$ \\
Bangsalsari & $9.945,80$ \\
Panti & $3.392,42$ \\
Sukorambi & $1.425,00$ \\
Arjasa & $2.519,10$ \\
\hline
\end{tabular}

Sumber: Dinas Pertanian Tanaman Pangan, Holtikultura dan Perkebunan Kabupaten Jember, 2016

Tabel 2. Kelompok tani Kecamatan Bangsalsari

\begin{tabular}{llc}
\hline Desa & $\begin{array}{l}\text { Nama Kelompok } \\
\text { tani }\end{array}$ & Anggota \\
\hline Curah & Sumber Klopo 1 & 319 \\
Kalong & & \\
& Sumber Klopo 2 & 219 \\
Tugusari & Sidomakmur & 65 \\
& Andongsari & 446 \\
Badean & Karangpakel & 38 \\
& Taman Glugo & 36 \\
& Jiro & 45 \\
Banjarsari & Mudimakmur & 65 \\
\hline
\end{tabular}

Sumber: Data diolah, 2018

Kelompok tani tingkat desa di Kecamatan Bangsalsari yaitu Desa Tugusari dan Curah Kalong memiliki jumlah anggota lebih banyak dan lahan yang lebih luas dibandingkan desa lain. Selain itu kedua desa ini berada pada ketinggian yang cukup mendukung untuk pertumbuhan kopi robusta sehingga Desa Tugusari dan Curah Kalong memiliki potensi yang cukup baik dalam perkebunan rakyat khususnya kopi. Batas-batas wilayah Desa Tugusari dan Desa Curah Kalong ditunjukkan pada Tabel 3. 
Tabel 3. Batas wilayah Desa Tugusari dan Desa Curah Kalong

\begin{tabular}{|c|c|c|}
\hline $\begin{array}{l}\text { Batas } \\
\text { Desa }\end{array}$ & Desa Tugusari & $\begin{array}{l}\text { Desa Curah } \\
\text { Kalong }\end{array}$ \\
\hline $\begin{array}{l}\text { Sebelah } \\
\text { Utara }\end{array}$ & $\begin{array}{l}\text { Lereng pegunungan } \\
\text { Argopuro } \\
\text { (PERHUTANI) }\end{array}$ & $\begin{array}{l}\text { Lereng } \\
\text { pegunungan } \\
\text { Argopuro }\end{array}$ \\
\hline Sebelah & Desa Banjarsari dan & Desa \\
\hline Selatan & Langkap & Gambirono \\
\hline Sebelah & Desa Curah Kalong & Desa \\
\hline Barat & & Klatakan \\
\hline Sebelah & Desa Banjarsari dan & Desa \\
\hline Timur & Desa Badean & Tugusari \\
\hline
\end{tabular}

Sumber: Profil Desa Tugusari dan Curah Kalong, 2018

Anggota kelompok tani di Desa Tugusari dan Curah Kalong selain menanam kopi juga bercocok tanam pisang, lada dan sengon laut dengan sistem penanaman tumpang sari. Tumpang sari merupakan sistem penanaman yang memiliki tujuan untuk memanfaatkan lahan secara maksimal. Penanaman tumpang sari dilakukan dengan memanfaatkan lahan sisa atau di selasela tanaman pokok (Windasari dan Budhi, 2013). Selain itu sistem penanaman tumpang sari dapat mengefisiensikan pemakaian pupuk dan pestisida, mengurangi erosi, konservasi lahan serta mendapatkan total produksi yang lebih besar dibandingkan penanaman secara monokultur.

\section{Rantai Pasok Kopi Robusta Kecamatan Bangsalsari Kabupaten Jember}

Rantai pasok kopi robusta merupakan perjalanan komoditas pertanian kopi mulai dari petani hingga ke konsumen. Namun, dalam penelitian ini untuk pola rantai pasoknya dibatasi hingga aktor eksportir saja. Gambar 1 menunjukkan pola sistem rantai pasok kopi robusta Pegunungan Argopuro Kecamatan Bangsalsari Jember.

Pola struktur rantai pasok pada Gambar 1 menjelaskan bahwa produk kopi robusta Pegunungan Argopuro Kecamatan Bangsalsari Jember melalui beberapa aktor (pelaku rantai pasok) mulai dari petani, pedagang pengumpul, pedagang besar, eksportir dan lembaga terkait. Aliran produk kopi dari petani berupa biji kopi kering (ose) dijual kepada pedagang pengumpul di tingkat desa. Petani biasanya langsung mendapatkan uang hasil penjualan kopi tersebut pada hari yang sama. Beberapa petani masih melakukan sistem ijon dengan menerima uang terlebih dahulu sebelum buah kopi matang sempurna. Hal ini dilakukan karena petani ingin segera memperoleh pendapatan meskipun terkadang petani juga dirugikan dengan sistem ijon tersebut. Sistem ijon merupakan kegiatan petani rakyat kopi dalam melakukan penjualan pada saat buah kopi belum terbentuk sempurna (Sukardi, 2017). Petani

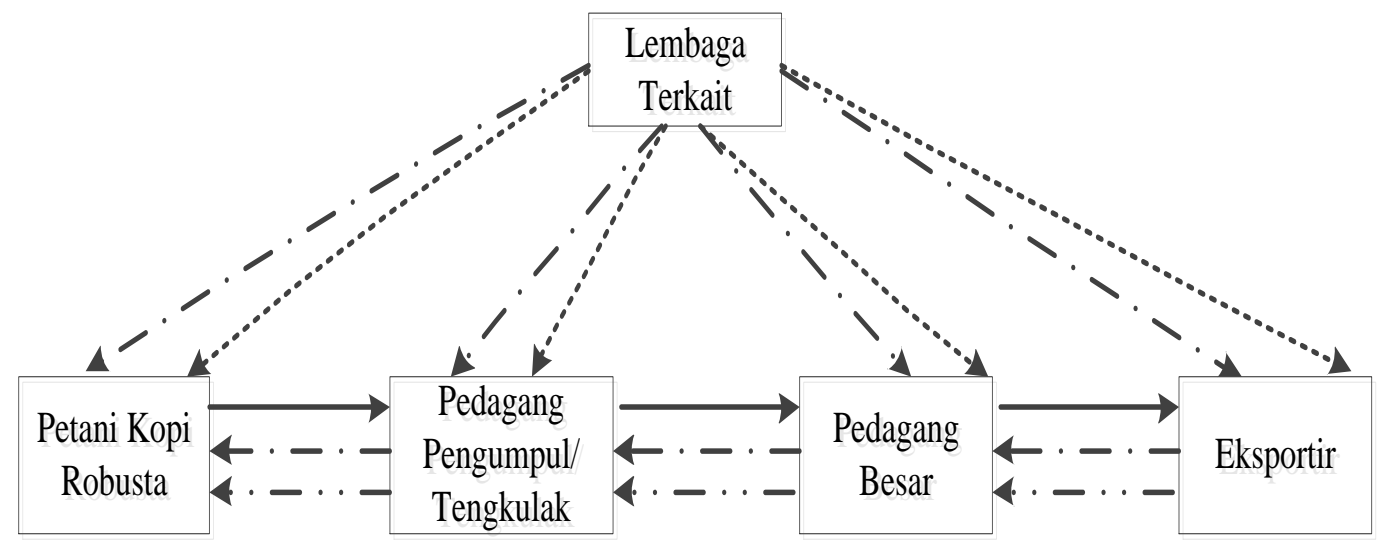

Gambar 1. Struktur rantai pasok kopi robusta meliputi aliran produk ( $\longrightarrow$ ), aliran informasi $(-\cdot-\cdot>)$, aliran finansial $(-\cdots \rightarrow)$, dan aliran jasa $(\cdots \cdots \cdots+\cdots)$ 
melakukan pemetikan buah kopi tanpa membedakan antara buah merah maupun yang masih hijau. Cara ini dilakukan karena lebih cepat pengerjaannya dan sistem ijon yang diterapkan. Karena tidak memisahkan antara kopi merah dan kopi hijau maka terdapat banyak biji cacat, rusak dan berjamur pada biji kopi sudah kering. Sistem ijon menyebakan kerugian karena harga kopi tidak sesuai dengan harga pasar, sehingga kegiatan ini menimbulkan risiko terutama pada harga kopi (Zainuddin et al., 2015).

Kopi dari pedagang pengumpul selanjutnya dijual kepada pedagang besar. Proses pencairan uang dari penjualan kopi pedagang pengumpul ke pedagang besar tidak memakan waktu yang terlalu lama yaitu sekitar 1 sampai 2 hari. Hal ini tergantung perputaran uang dari modal yang dimiliki pedagang besar. Semakin banyak modal yang dimiliki pedagang besar maka pencairan uang hasil penjualan kopi pedagang pengumpul semakin cepat pula.

Perjalanan kopi selanjutnya yaitu dari pedagang besar dijual kepada eksportir. Kegiatan ini biasanya membutuhkan satu hingga dua hari perjalanan, tergantung dari jarak, jalur dan transportasi yang digunakan. Eksportir kopi robusta yang membeli kopi ose dari Kecamatan Bangsalsari yaitu PT. Olam Indonesia dan PT. Indocom Citra Persada. Proses pencairan uang hasil penjualan kopi dilakukan secara tunai langsung atau melalui transfer tergantung dari banyaknya kopi yang dijual oleh pedagang besar.

Aliran informasi dan finansial merupakan kebalikan dari aliran produk. Eksportir sebelum membeli produk kopi robusta telah memberikan beberapa informasi terkait dengan harga kopi robusta per kilogram, patokan kualitas sesuai dengan harga tersebut dan lainnya. Informasi dari eksportir ini pertama kali disampaikan kepada pedagang besar dan lembaga terkait (penyuluh) melalui via telepon dan pesan singkat. Informasi yang telah sampai ke pedagang besar selanjutnya secara berantai aktor-aktor menyampaikan hingga kepada petani. Pola struktur rantai pasok kopi robusta sesuai dengan pendapat Kambey et al. (2016) bahwa supply chain menyangkut hubungan yang terus-menerus mengenai produk, uang dan informasi. Produk umumnya mengalir dari hulu ke hilir, uang mengalir dari hilir ke hulu, sedangkan informasi mengalir baik dari hulu ke hilir maupun hilir ke hulu.

\section{KESIMPULAN}

Analisis mengenai manajemen rantai pasok kopi robusta di Kecamatan Bangsalsari Kabupaten Jember menghasilkan struktur rantai pasok melalui beberapa anggota rantai pasok atau disebut aktor. Anggota rantai pasok tersebut adalah petani, pedagang pengumpul, pedagang besar, eksportir dan lembaga terkait. Pola struktur rantai pasok terdapat pada aliran produk, informasi, finansial dan jasa.

\section{DAFTAR PUSTAKA}

Aini, H., Syamsun, M., dan Setiawan, A. 2014. Analisis risiko rantai pasok kakao di Indonesia dengan metode analytic network process dan failure mode effect analysis terintegrasi. Jurnal Manajemen dan Agribisnis, 11 (3): 209-219.

Budiono, R., dan Syaichu, A. 2016. Manajemen rantai pasokan jagung asalan pada CV Amin di Lampung Tengah. Jurnal Spektrum Industri, 14 (2): 109-230.

Direktorat Jenderal Perkebunan. 2011. Statistik Perkebunan Kopi Rakyat Kabupaten Jember Tahun 2010. Sekretariat Direktorat Jenderal Perkebunan, Direktorat Jenderal Perkebunan, Kementerian Pertanian, Jakarta.

Direktorat Jenderal Perkebunan. 2016. Statistik Perkebunan Indonesia Kopi 2015-2017. Sekretariat Direktorat Jenderal Perkebunan, Direktorat Jenderal Perkebunan, Kementerian Pertanian, Jakarta. 
Kambey, S.F., Kawet, L., dan Sumarauw, J.S.B. 2016. Analisis rantai pasok (supply chain) kubis di Kelurahan Rurukan Kota Tomohon. Jurnal EMBA, 4 (5): 303-408.

Nesti, L., Shoffiyati, P., dan Chairun, N. 2016. Pemodelan praktik manajemen rantai pasok dan budaya organisasi terhadap kinerja rantai pasok dengan studi kasus: Sub-sektor industri makanan ringan berbasis umbi-umbian di Kota Padang. Jurnal Agroteknologi, 10 (2): 153-159.

Purnomo, B.H., Rusdianto, A.S., dan Dewi, Y.W. 2014. Formulasi strategi rantai pasok tepung terigu untuk industri kecil menengah di Kabupaten Jember, Jurnal Agroteknologi, 8 (2): 140-152.

Pusat Data dan Sistem Informasi Pertanian. 2016. Outlook Kopi. Kementerian Pertanian, Jakarta.

Sukardi, S. 2017. Analisis pendapatan masyarakat desa untuk kelestarian hutan lindung (studi hutan desa Patteneteang Kabupaten Bantaeng). Jurnal Hutan dan Masyarakat, 9 (1): 44-53.

Suryaningrat, I. B. 2016. Implementation of QFD in food supply chain management: a case of processed cassava product in Indonesia. Advance Science Engineering Information Technology, 6 (3): 2088-5334.

Windasari, N.P.V., dan Budhi, M.K.S. 2013. Analisis pengaruh tumpangsari terhadap pendapatan petani di Desa Munduktemu Kabupaten Tabanan. EJurnal Ekonomi Pembangunan Unud., 2 (5): 254-259.

Zainuddin, S., Martini, E., Perdana, A., dan Roshetko, M. 2015. Kualitas, kuantitas dan pemasaran kopi arabika dari kebun agroforestry di Kabupaten Bantaeng, Sulawesi Selatan. Prosiding Seminar Nasional Agrofestry. Bandung, 12 November 2015. 